\section{Laser light}

Plasmas and Laser Light. By T. P. Hughes. Pp. xxi+518. (Adam Hilger: London, October 1975.) $£ 35$.

LASER-related topics now hit the scientific headlines so frequently that it can become quite difficult to distinguish between actual achievement and future plans or aspirations. Confusion of this sort is perhaps inevitable in a field which is interdisciplinary, and which is still growing very rapidly. For example, in the US the relevant ERDA operating budget (supporting research and development administered by the Energy Research and Development Administration), currently totals some $\$ 90$ million per annum. Research into laser isotopeseparation techniques now constitutes a significant fraction of this budget, but laser fusion still continues to attract the lion's share of the funding. Within the UK a laser facility for fundamental scientific investigations has recently been established at the SRC's Rutherford Laboratory. In view of all the above developments, the recent publication of Dr Hughes' book is particularly opportune.

The historical background, some potential advantages, possible difficulties and competition for the lasercompression approach to controlled thermonuclear fusion have been outlined by me on previous occasions (Nature, 239, 129 (1972); 251, 99 and 252, 631 (1974)). These topics constitute the dominant theme of the book, although magnetic containment and plasma diagnostics are also discussed briefly. Plasmas and Laser Light is a broad canvas and Dr Hughes has appropriately included an extensive treatment of ionisation and breakdown in gases and solids.

Some other sections of the book provide background information which is readily available elsewhere. In particular, much of the chapters dealing with small amplitude plasma waves, plasma spectroscopy, incoherent scattering and thermonuclear reactions have been the subject of previous specialist monographs. The main interest of this book, however, is its systematic treatment of the interaction of high intensity, coherent, light with solids, gases and plasmas, and its unifying, pedagogical treatment should therefore be of considerable value to students and younger research workers in the field. The discussion of published experimental work is very well illustrated with line diagrams, but is exhaustively comprehensive; thus the reference list is over 50 pages long. Errors in the text are few and trivial (for example, equation 2.87), and the cross referencing is excellent. It is in correct to suggest (p54) that laser fusion has introduced a completely new regime of plasma physics; for example, parametric interactions are well known from previous controlled theromonuclear reaction (CTR) work. It is also a pity that there was no discussion of impurity-resonance scattering, nor any pictorial illustration of the growth of hydrodynamic instabilities which have been predicted in two-dimensional laser-compression computer calculations, since these may both have important consequences. Indeed, the degree of spatial symmetry required of alternative laser-compression schemes could well determine the practical feasibility of these approaches to fusion (see Lawrence Livermore Report UCRL-50021-74, p355). With these caveats, the book seems wellbalanced, up-to-date, and a pleasure to read. It will certainly become a wellused text in departmental libraries, although a cheaper paperback edition might more realistically suit the pockets of many research students.

I. J. Spalding

\section{Excited states}

Excited States in Organic Chemistry. By J. A. Barltrop and J. D. Coyle. Pp. xii +376 . (Wiley: London and New York, 1975.) £15.

BEFORE 1965 there were few textbooks in photochemistry but, commencing with the books by Calvert and Pitts and by Turro, the situation has been transformed. Many books are now available and both beginner and expert are well catered for. As a consequence it is necessary for any new book to offer advantages in clarity of presentation, a wide coverage coupled with modernity, appeal to particular groups of chemists, and, not least, a reasonable price, before such a book can be assured of success.

This book is written in a clear, concise style, is adequately cross referenced and develops its material in a systematic fashion. Following an introductory chapter the basic theoretical foundations of the subject are expounded in three chapters (time-independent properties, timedependent properties and quenching of excited states). The methods specific to photochemistry are then dealt with in detail although the beginner would need to read other books to get a complete presentation of available techniques. A condensed treatment of orbital symmetry and photochemistry follows. The concluding five chapters deal with different chromophores- $\mathrm{C}=\mathrm{O}, \quad \mathrm{C}=\mathrm{C}$, aromatic nitrogen and saturated-the first three of which present the subject in considerable detail.
Both beginner and expert will profit from reading this authoritative work. The good undergraduate interested in photochemistry would grasp the scope of the subject although he would be more likely to purchase and use one of the smaller and cheaper books which give less detail and a more general coverage. The research student in photochemistry would find the book of considerable use and obtain a perspective for approaching the voluminous literature appearing annually in the Specialist Periodical Reports on Photochemistry. Experienced photochemists including inorganic and physical chemists would benefit from studying this book. It is not as encyclopaedic as Calvert and Pitts but this disadvantage is offset by being up-to-date, at least half of the basic material referenced having appeared since 1966; and in the later chapters dealing with the functional groups three-quarters of the material is new. The misprints are few and almost entirely trivial, with the exception of page 163 , where electrocyclic is misprinted as electrolytic. The price is prohibitive for a student. and unfortunately, will limit sales amongst the more specialist audience who will benefit most from reading this book.

B. G. Gowenlock

\section{BOOKS \\ ON PURE AND APPLIED SCIENCE}

Books reviewed or men-

tioned in this journal are available from stock.

Catalogues on application.

Please state interests.

\section{SCIENTIFIC LIBRARY}

ANNUAL SUBSCRIPTION from $£ 5.00$

Reduced rates for multiple subscriptions

Available in U.K. only

Prospectus free on request

\section{H. K. LEWIS \& Co. Ltd.}

LONDON: 136 GOWER STREET, WC1E 6BS

Telephone : $01-3874282$ 